\title{
Aspects of interest related to antiemesis in haematological patients
}

\begin{abstract}
Few side effects of cancer treatment are more fearsome for patients than nausea and vomiting. Although both can result from surgery or radiation therapy, chemotherapy-induced nausea and vomiting (CINV) are potentially the most severe and the most distressing ones. Despite recent advances in the prevention of emesis induced by chemotherapy, its control remains to be insufficient in $20-25 \% .^{1}$ of patients, with the ensuing negative impact on their quality of life. In this small review, we intend to analyze some critical aspects related to the approach of antiemetic therapy in the clinical practice in haematological patients.
\end{abstract}

Keywords: chemotherapy, radiation therapy, surgery, prophylaxis, antiemetic, cyclophosphamide, emetogenic, cytotoxic agents
Volume 7 Issue 2 - 2019

\author{
Maria Perfecta Fernandez Gonzalez,' Aurea \\ Maria Gomez Marquez,' Maria Pereiro \\ Sanchez, ${ }^{2}$ Raquel Iglesias Varela, ${ }^{2}$ Jose Luis \\ Sastre Moral ${ }^{2}$ Carlos Ulibarrena Redondo ${ }^{2}$ \\ 'Departament of Pharmacy, University Hospital of Ourense, \\ Spain \\ ${ }^{2}$ Departament of Haematology, University Hospital of Ourense, \\ Spain
}

Correspondence: Maria Perfecta Fernandez Gonzalez, Departament of Pharmacy, University Hospital of Ourense, Spain, Email maria.fernandez.ensayos@gmail.com

Received: August 18,2019 | Published: September 24, 2019
Abbreviations: CINV, chemotherapy-induced nausea and vomiting; ECG, electro-cardiogram; TdP, torsade de pointes; RA, receptor antagonists; NETU, Netupitant

\section{Introduction}

Good symptomatic control in haematological patients is essential not only to improve the quality of life but also to maintain the intensity of treatment and that the patient's prognosis is not compromised. A greater knowledge of the factors affecting the control of nausea and vomiting are keys to improving the situation:

a. Several studies have shown that there is a difference between the perception of CINV by the health care provider and patients, thus leading to a general underestimation of the risk of CINV.,

b. Another important issue is that most clinical trials evaluating CINV have focused on antiemetic prophylaxis for solid tumor chemotherapy. Consequently, evidenced-based guidelines for antiemetic prophylaxis with haematological malignancies cytotoxic agents are not well established. The definition of AC regimens (Adriamycin plus cyclophosphamide) as highly emetogenic came exclusively from studies of women with breast cancer. It is not clear whether other combination regimens used within $\mathrm{AC}$ in other diseases or in more diverse groups of subjects: For example, in non-Hodgkin lymphoma, CHOP (doxorubicin plus cyclophosphamide, vincristine and prednisone) would be highly emetogenic.

c. Moreover, it should be noted that most regimens of haematological chemotherapy, include more than one agent and a multiday therapy. This situation adds an extra complexity. Patients, who receive multiday chemotherapy, are at risk of suffering both acute and delayed nausea and vomiting.

d. Current recommendations are based on the emetogenic potential of cytotoxic agents. However, there are some factors related to the patient's condition which have been usually overloaded.

\section{Role of NK I receptor antagonists (NKIRA)}

Aprepitant and fosaprepitant, $\mathrm{NK}_{1} \mathrm{R}$ antagonists, have a moderate inhibition effect on the cytochrome $\mathrm{CYP}_{3} \mathrm{~A}_{4}\left(\mathrm{P}_{450} 3 \mathrm{~A}_{4}\right.$ enzyme), which has a special relevance in drug metabolism. ${ }^{4} \mathrm{CYP}_{3} \mathrm{~A}_{4}$ is responsible for the metabolism of glucocorticoids, and thus, few clinical trials recommend the reduction of dexametasone from 20 to $12 \mathrm{mg}$ on first day and from $8 \mathrm{mg}$ twice daily to $8 \mathrm{mg}$ daily on days two and three when given in combination with aprepitant. ${ }^{5-7}$ This dose reduction applies only when glucocorticoids are used as antiemetic in conjunction with $\mathrm{NK}_{1} \mathrm{RA}$, not when given as an antitumor agent as part of the chemotherapy scheme. Many combinations of drugs used for the treatment of malignant homeopathies include corticosteroids, strengthening the need for using $\mathrm{NK}_{1} \mathrm{R}$ antagonists with caution in this type of patients.

In addition, it is supposed that aprepitant can decrease the clearance of drugs metabolized by $\mathrm{CYP}_{3} \mathrm{~A}_{4}$ such as cyclophosphamide, docetaxel, etoposide, irinotecan or Vinca alkaloids, resulting in extended exposure and increased toxicity. However, there is no clinical evidence that this actually occurs. ${ }^{7,8}$

\section{Role of palonosetron}

Palonosetron, a second-generation agent, has a 30-100 fold higher affinity for the 5- $\mathrm{HT}_{3}$ receptor and a salient longer half life (40hours) in comparison to first-generation $5-\mathrm{HT}_{3}$ receptor antagonists $\left(5-\mathrm{HT}_{3}\right.$ RA) such as granisetron, ondansetron and dolasetron.

Besides, palonosetron, as a single agent, is more effective than ondansetron or dolasetron in prevention of emesis owing to chemotherapy agents with different emetogenic potential. ${ }^{9-11}$ This was reflected in the results of a multicenter trial in 592 patients, most of them had received doxorubicin and cyclophosphamide (AC) for breast cancer; a small group of subjects were treated with cisplatin/carboplatin based chemotherapy regimens. ${ }^{9}$ Patients were randomly assigned to a single intravenous dose of palonosetron at 0.25 or $0.75 \mathrm{mg}$ or dolasetron at $100 \mathrm{mg}$. More patients treated with 
palonosetron $(0.25 \mathrm{mg})$ have achieved control of both acute $(63 \%$ vs $53 \%$ ) and delayed emesis ( $54 \%$ vs $39 \%$ ) compared with dolasetron. The dose of $0.75 \mathrm{mg}$ was not significantly superior in comparison with $0.25 \mathrm{mg}$.

Another trial with similar design as mentioned above, has also demonstrated better results for palonosetron versus ondansetron. ${ }^{10}$ Additionally, palonosetron plus glucocorticoids, provides a better control of delayed emesis in comparison with first generation 5-HT RA combined with glucocorticoids. ${ }^{12-14}$ In hematological setting, particularly in patients with non Hodgkin lymphoma, an open label trial with a single arm, has found that overall complete response rate of $86 \%$ was reached with a single dose of $0.25 \mathrm{mg}$ intravenously palonosetron administered prior to chemotherapy: $75 \%$ receiving CHOP plus rituximab. ${ }^{15}$ Palonosetron has also shown efficacy in patients who underwent hematopoietic transplantation with high dose therapy conditioning regimens such as melphalan given intravenously at a total dose of $200 \mathrm{mg} / \mathrm{m}^{2}$ divided over two consecutive days ${ }^{16}$

\section{Safety aspects}

Changes in the electrocardiogram interval (ECG) are a class effect of first generation 5- $\mathrm{HT}_{3} \mathrm{RA}$, although they have not been reported with both transdermal or prolonged-release subcutaneous granisetron formulations. ${ }^{17,18}$

Changes in the ECG interval appear to be more pronounced between one-two hours after a dose has been administered. They are usually not clinically significant and in 24 hours this effect is reversed. ${ }^{19-21}$ However, potentially fatal cardiac arrhythmias, including Torsade de pointes (TdP), have been reported in relation to QTc prolongation. ${ }^{19-23}$ The FDA has warned about potentially fatal cardiac arrhythmias related to QT prolongation in subjects treated with ondansetron. ${ }^{24} \mathrm{QT}$ prolongation appears to be a dose dependent effect and, particularly, an intravenous single dose of $32 \mathrm{mg}$ would be enough to trigger this adverse event.

In the United States it is recommended not to exceed the dose of $16 \mathrm{mg}$ given intravenously. In patients with congenital long QT syndrome avoid use of ondansetron and monitoring ECG in special populations, such as those with hypo kalemia or hypo-magnesaemia, heart failure, and Brady-arrhythmias, and in patients taking other medications that could increase the risk of QTc prolongation. As opposed to first generation 5-HT 3 RA, QTc prolongation has not been documented with palonosetron. ${ }^{25,26}$

\section{Role of netupitant + palonosetron}

Netupitant (NETU) is a new highly selective $\mathrm{NK}_{1}$ RA that has been formulated in combination with palonosetron as an oral fixed dose (AKYNZEO ${ }^{\circledR}$, also known as NEPA). Palonosetron was selected for the AKYNZEO ${ }^{\circledR}$ combination because of its interesting pharmacological ${ }^{27}$ and clinical ${ }^{28}$ profile. Palonosetron is distinguished from first generation 5- $\mathrm{HT}_{3}$ RAs because of its singular receptor binding, its ability to promote $\mathrm{NK}_{1}$ receptor internalization and its synergistical effect associated to NETU in the inhibition of the substance $\mathrm{P}$ response, as well as its remarkable better efficacy in delayed emesis. ${ }^{27,29-30}$ Accordingly, it has the potential to increase prophylaxis of delayed CINV when used combined with NETU. Another interesting aspect is that NEPA formulation may improve guideline adherence by targeting two critical pathways involved in emesis with a convenient, single oral dose and having an effect on acute and delayed emesis.

\section{Role of olanzapine}

Olanzapine is a second generation antipsychotic that blocks serotonin type two 5-hydroxytryptamine receptors $\left(5-\mathrm{HT}_{2}\right)$ and dopamine receptors (D2). In a double-blind randomized trial involving 80 patients receiving highly emetogenic chemotherapy, superiority for olanzapine was shown over metoclopramide for treatment of breakthrough nausea and vomiting. Olanzapine was administered $10 \mathrm{mg}$ orally, daily for 3 days and metoclopramide $10 \mathrm{mg}$ orally; three times daily during 3 days,${ }^{31}$ during the observation period (72hours), more subjects receiving olanzapine had no nausea $(68 \%$ vs $23 \%)$ and no recurrent emesis ( $70 \%$ vs $31 \%)$. These data suggest that olanzapine is preferred over metoclopramide alone. Even if the optimal dose is not well established, it is expected that a lower dose could provide similar efficacy with a more favorable side effect profile. ${ }^{32-33}$

Emesis is a very common adverse reaction to chemotherapy that is generally predictable and potentially preventable. The main goal of antiemetic therapy is to control emesis in all situations without adding side effects. In addition, a secondary objective would be controlling or reducing the number of hospitalizations and therefore optimizing the use of health resources. It is very important to carry out preventive measures from the first cycle because a good prophylaxis can reduce the risk of developing nausea and anticipatory vomiting throughout the treatment, as well as the negative impact that both entail.

\section{Acknowledgments}

None

\section{Conflicts of interest}

The author declares that there are no conflicts of interest.

\section{References}

1. Nasir SS, Schwartzberg LS. Recent advances in preventing chemotherapy- induced nausea and vomiting. Oncology (Williston Park, NY). 2016;30(8):750-762.

2. Grunberg SM, Deuson RR, Mavros P, et al. Incidence of chemotherapyinduced nausea and emesis after modern antiemetics. Cancer. 2004;100(10):2261-2268.

3. Liau C, Chu N, Liu H, et al. Incidence of chemotherapy-induced nausea and vomiting in Taiwan: Physicians' and nurses' estimation vs. patients ' reported outcomes. Support Care Cancer. 2005;13(5):277-286.

4. McCrea JB, Majumdar AK, Goldberg MR, et al. Effects of the neurokinin1 receptor antagonist aprepitant on the pharmacokinetics of dexamethasone and methylprednisolone. Clin Pharmacol Ther. 2003;74(1):17-24.

5. Hesketh PJ, Grunberg SM, Gralla RJ, et al. The oral neurokinin-1 antagonist aprepitant for the prevention of chemotherapy-induced nausea and vomiting: a multinational, randomized, double-blind, placebocontrolled trial in patients receiving high-dose cisplatin--the Aprepitant Protocol 052 Study Group. J Clin Oncol. 2003;21(22):4112-4119.

6. Poli-Bigelli S, Rodrigues-Pereira J, Carides AD, et al. Addition of the neurokinin 1 receptor antagonist aprepitant to standard antiemetic therapy improves control of chemotherapy-induced nausea and vomiting. Results from a randomized, double-blind, placebo-controlled trial in Latin America. Cancer. 2003; 97(12):3090-3098.

7. Warr DG, Hesketh PJ, Gralla RJ, et al. Efficacy and tolerability of aprepitant for the prevention of chemotherapy-induced nausea and vomiting in patients with breast cancer after moderately emetogenic chemotherapy. J Clin Oncol. 2005; 23(12):2822-2030. 
8. Nygren P, Hande K, Petty KJ, et al. Lack of effect of aprepitant on the pharmacokinetics of docetaxel in cancer patients. Cancer Chemother Pharmacol. 2005;55(6):609-616.

9. Eisenberg P, Figueroa-Vadillo J, Zamora R, et al. Improved prevention of moderately emetogenic chemotherapy-induced nausea and vomiting with palonosetron, a pharmacologically novel $5-\mathrm{HT}_{3}$ receptor antagonist: results of a phase III, single-dose trial versus dolasetron. Cancer. 2003;98(11):2473-2482.

10. Gralla R, Lichinitser M, Van Der Vegt S, et al. Palonosetron improves prevention of chemotherapy-induced nausea and vomiting following moderately emetogenic chemotherapy: results of a double-blind randomized phase III trial comparing single doses of palonosetron with ondansetron. Ann Oncol. 2003;14(10):1570-1577.

11. Likun Z, Xiang J, Yi B, et al. A systematic review and meta-analysis of intravenous palonosetron in the prevention of chemotherapy-induced nausea and vomiting in adults. Oncologist. 2011;16(2):207-216.

12. Saito M, Aogi K, Sekine I, et al. Palonosetron plus dexamethasone versus granisetron plus dexamethasone for prevention of nausea and vomiting during chemotherapy: a double-blind, double-dummy, randomised, comparative phase III trial. Lancet Oncol. 2009;10(2):115-124.

13. Aapro MS, Grunberg SM, Manikhas GM, et al. A phase III, doubleblind, randomized trial of palonosetron compared with ondansetron in preventing chemotherapy-induced nausea and vomiting following highly emetogenic chemotherapy. Ann Oncol. 2006;17(9):1441-1449.

14. Kubota K, Saito M, Aogi K, et al. Control of nausea with palonosetron versus granisetron, both combined with dexamethasone, in patients receiving cisplatin- or anthracycline plus cyclophosphamide-based regimens. Support Care Cancer. 2016;24(9):4025-4033.

15. Di Renzo N, Montanini A, Mannina D, et al. Single-dose palonosetron for prevention of chemotherapy-induced nausea and vomiting in patient with aggressive non-Hodgkin's lymphoma receiving moderately emetogenic chemotherapy containing steroids: results of a phase II study from the Gruppo Italiano per lo Studio dei Linfomi (GISL). Support Care Cancer. 2011;19(10):1505-1510.

16. Gomez Marquez AM, Casado Vazquez L, Saenz Fernandez CA Revision of nausea and vomiting in patients with haematological malignancies and hematopoietic transplantation. Hematol Transfus Int J. 2017;4(3):80-82

17. Mason JW, Selness DS, Moon TE, et al. Pharmacokinetics and repolarization effects of intravenous and transdermal granisetron. Clin Cancer Res. 2012;18(10):2913-2921.

18. Mason JW, Moon TE, O'Boyle E, et al. A randomized, placebocontrolled, four-period crossover, definitive QT study of the effects of APF530 exposure, high-dose intravenous granisetron, and moxifloxacin on QTc prolongation. Cancer Manag Res. 2014;6:181-190.
19. Navari RM, Koeller JM. Electrocardiographic and cardiovascular effects of the 5-hydroxytryptamine3 receptor antagonists. Ann Pharmacother. 2003;37(9):1276-1286.

20. Pinarli FG, Elli M, Dagdemir A, et al. Electrocardiographic findings after 5-HT3 receptor antagonists and chemotherapy in children with cancer. Pediatr Blood Cancer. 2006;47(5):567-571.

21. Keller GA, Ponte ML, Di Girolamo G. Other drugs acting on nervous system associated with QT-interval prolongation. Curr Drug Saf. 2010; 5(1):105-111.

22. Turner S, Mathews L, Pandharipande $\mathrm{P}$, et al. Dolasetron-induced torsades de pointes. J Clin Anesth. 2007;19(8):622-625.

23. US Food and Drug Administration. Zofran (ondansetron): Drug Safety Communication - Risk of Abnormal Heart Rhythms. 2011.

24. http://healthycanadians.gc.ca/recall-alert-rappel-avis/hcsc/2014/39943a-eng.php

25. Morganroth J, Flaharty KK, Parisi S, et al. Effect of single doses of IV palonosetron, up to $2.25 \mathrm{mg}$, on the QTc interval duration: a doubleblind, randomized, parallel group study in healthy volunteers. Support Care Cancer. 2016;24(2):621-627.

26. Feyer P, Jordan K. Update and new trends in antiemetic therapy: the continuing need for novel therapies. Ann Oncol. 2011;22(1):30-38.

27. Stathis M, Pietra C, Rojas C, et al. Inhibition of substance P-mediated responses in NG108-15 cells by netupitant and palonosetron exhibit synergistic effects. Eur J Pharmacol. 2012;689(1-3):25-30.

28. Rojas C, Slusher BS. Pharmacological mechanism of 5-HT3 and tachykinin NK-1 receptor antagonism to prevent chemotherapy-induced nausea and vomiting. Eur J Pharmacol. 2012;684(1-3):1-7.

29. Thomas AG, Stathis M, Rojas C, et al. Netupitant and palonosetron trigger NK1 receptor internalization in NG 108-15 cells. Exp Brain Res. 2014;232(8):2637-2644.

30. Navari RM, Nagy CK, Gray SE. The use of olanzapine versus metoclopramide for the treatment of breakthrough chemotherapyinduced nausea and vomiting in patients receiving highly emetogenic chemotherapy. Support Care Cancer. 2013;21(6):1655-1663.

31. Hashimoto H, Takako Yanai, Kengo Nagashima, et al. A double-blind randomized phase II study of 10 versus $5 \mathrm{mg}$ olanzapine for emesis induced by highly emetogenic chemotherapy with cisplati (abstract). $J$ Clin Oncol. 2016.

32. FDA safety communication.

33. Gonullu G, Demircan S, Demirag MK, et al. Electrocardiographic findings of palonosetron in cancer patients. Support Care Cancer. 2012;20(7):1435-1439. 